\title{
Análisis del tratamiento de contenidos en la creación de audiovisuales educativos
}

\author{
Javier Manso Lorenzo \\ Dpto. Didáctica de las Ciencias Experimentales, Sociales y Matemáticas.Universidad Complutense de \\ Madrid.jmanso@educa.madrid.org \\ ORCID: https://orcid.org/0000-0003-1942-7218
}

Ángel Ezquerra

Dpto. Didáctica de las Ciencias Experimentales, Sociales y Matemáticas. Universidad Complutense de Madrid.angel.ezquerra@edu.ucm.es

ORCID: http:/ / orcid.org/0000-0002-5736-9867

$\mathbf{M}^{\mathrm{a}}$ Esther Burgos Jiménez

Dpto. Didáctica de las Ciencias Experimentales, Sociales y Matemáticas. Universidad Complutense de Madrid.esther.bur.j@gmail.com

ORCID: bttps:/ / orcid.org/0000-0003-3379-4444

\author{
Joseph Mafokozi \\ Dpto.Investigación y Psicología en Educación.Universidad Complutensede Madrid.mafjos@edu.ucm.es \\ ORCID: https:// orcid.org/0000-0002-6674-2387
}

[Recibido: 4 Febrero 2018. Revisado: 2 Junio 2018. Aceptado: 25 Agosto 2018]

\begin{abstract}
Resumen: El alumnado actual, inmerso en una sociedad repleta de datos, está acostumbrado a gestionar y comunicarse de modo audiovisual en su día a día. Sin embargo, desde el punto de vista académico este aspecto tecnológico -el audiovisual- no está suficientemente integrado en el proceso enseñanza-aprendizaje. Uno de los motivos parece deberse a la escasa formación del profesorado en esta forma de comunicación. En este trabajo, se plantea la elaboración de un documental escolar sobre un tópico de ciencia a alumnos del Grado de Primaria y del Máster de Secundaria, y se analiza cómo evolucionan los contenidos propuestos por los estudiantes en cada uno de los pasos seguidos. Puede destacarse que con el cambio de formato de texto a vídeo el tratamiento de los contenidos cambió. En concreto, la necesidad de redactar un guion forzó a los estudiantes a incorporar una trama argumental en la que engarzar los contenidos escolares. Esta necesidad discursiva forzó la búsqueda de situaciones reales y la consecuente ubicación de los contenidos escolares en unos más cercanos al alumnado. Esto facilitó la aparición de sus intereses, la vinculación entre su mundo y el contexto académico y, todo ello, con su modo de expresarse. Por otra parte, la incorporación de imágenes obligó a los futuros profesores a mostrar ordenadamente los hechos; tuvieron que considerar qué elementos visuales eran prioritarios, cuáles secundarios, cómo vincularlos, cómo indicar al espectador dónde mirar y cómo mirar. En definitiva, estos procedimientos expresados en imágenes pasaron a ser contenidos de aprendizaje en sí mismos.
\end{abstract}

Palabras clave: Formación del profesorado; Enseñanza de las ciencias; Nuevas metodologías; Audiovisual educativo; Imagen.

Analysis of the content treatment on the creation of educative audiovisual

Abstract: Nowadays, students are get used to communicate themselves and manage huge amount of data due to current society is based on audiovisual. However, these aspects are not considered enough from a teachinglearning process point of view. One of the reasons seems to be due to the fact teachers have a limited training in this way of communication. In this work, the elaboration of an educative audiovisual on a topic of science is proposed to students of the Master's Degree in Secondary School and Bachelor's Degree in Primary Education, and the evolution of the contents proposed by the students through each of the steps followed is analyzed. It can be highlighted a change of the content treatment from initial Script to final Video. In particular, writing a Script forced students to incorporate a plot story where academic contents were exposed. Consequently, they carried out a searching of real situations with the aim to situate the school contents closer to pupils. In this way, their interest awoke and they looked for a connection between their reality and the academic context. Besides,

\author{
Revista Eureka sobre Enseñanza y Divulgación de las Ciencias \\ Universidad de Cádir. APAC-Eureka. ISSN: 1697-011X \\ http://dx.doi.org/10.25267/Rev_Eureka_ensen_divulg_cienc.2019.v16.i1.1601 \\ http:// reuredc.uca.es
}


incorporating images made future teachers show the facts one after another; they had to consider which elements were more important and indicate viewer where and how he must look at. In short, these procedures based on images turned into learning contents by themselves.

Keywords: Teacher training; Science teaching; New methodologies; Educative audiovisual; Image.

Para citar este artículo: Manso, J., Ezquerra, A., Burgos, M. E., Mafokozi, J. (2019) Análisis del tratamiento de contenidos en la creación de audiovisuales educativos. Revista Eureka sobre Enseñanza y Divulgación de las Ciencias 16(1), 1601. doi: 10.25267/Rev_Eureka_ensen_divulg_cienc.2019.v16.11.1601

\section{Introducción}

Los cambios que afectan al desarrollo de nuestra sociedad parecen solicitar estrategias de enseñanza-aprendizaje acordes con los nuevos modos de generar, almacenar y transmitir la información. Sin embargo, las instituciones educativas se han ido construyendo y consolidando durante siglos, por lo que es difícil que se produzcan modificaciones a corto plazo (Adell 1997). En el campo que nos atañe, la Enseñanza de las Ciencias, debemos pensar en las modificaciones debidas a estos cambios y cómo debemos actuar para ser capaces de superar los estilos de enseñanza tradicionales (Gómez e Insausti 2004). Hay que tener en cuenta que no se ha ahondado aún suficientemente - desde las investigaciones en Didáctica de las Ciencias Experimentales- en la relación entre la actividad docente y el vínculo que tiene el alumnado con esta sociedad de la información y la comunicación (Ezquerra 2010). Así, aún se observa en la Enseñanza de las Ciencias un encuadre transmisivo (Oliva y Acevedo 2005, Martínez-Chico 2013). En él, el profesor actúa de principal transmisor de información, siendo el alumno un mero receptor de la misma con una mínima participación en la dinámica de la clase. Sin embargo, se hacen necesarios nuevos planteamientos metodológicos, más vinculados a la realidad social y cultural en la que vive el alumnado (Torres 2010). En este contexto surgieron las nuevas tecnologías. Estos modos de comunicación han propiciado un replanteamiento de los modelos tradicionales de enseñanza-aprendizaje, aportando nuevos procesos más flexibles (Salinas 2004). Estas reflexiones han permitido llevar a cabo propuestas para sustituir la enseñanza basada en la mera transmisión de información por otra en la que los estudiantes puedan formar parte de la construcción de su propio conocimiento, situando el aprendizaje en una actividad investigadora (Vilches y Gil 2007).

Parece que, de algún modo, la realidad actual centrada en las Tecnologías de la Información y la Comunicación (TIC) se impone, y puede forzar esa transformación que se planteaba desde hace años. Según Pontes (2005) es importante la formación del profesorado para sacar provecho de estas herramientas tecnológicas mediante un cambio metodológico que "favorežca la reflexión y la interacción de los alumnos". Dada la multitud de recursos TIC con los que contamos actualmente, es fundamental que su utilización se plantee con metodologías adecuadas, para que de este modo se produzca una verdadera mejora en la calidad de la educación científica (Novak, Patterson, Gavrin y Christian 1999). Entre todos las formas que adoptan las nuevas tecnologías nos interesan especialmente los audiovisuales en todos sus formatos (TV, vídeos y postcards en YouTube y otros canales, vídeos en webs, uso de vídeo en móviles, etc.). Los alumnos llevan a cabo numerosas acciones en torno a los formatos de este tipo, por lo que resulta necesario prestarles atención desde el ámbito educativo (Fischman 2001, Shu-LingLai 2000).

Inicialmente, puede considerarse un audiovisual como un reflejo de la propia realidad. Sin embargo, un vídeo no es solo un conjunto de estímulos que nos permiten repetir la realidad. El mensaje audiovisual permite describir hechos, discriminar información, relacionar contenidos, emocionar..., (Ezquerra 2010) en definitiva, posibilita conducir la mirada del alumno con una intención concreta (Ezquerra 2011). Además, la selección de la información 
que se lleva a cabo en la elaboración de los contenidos educativos está dirigida por los modelos mentales de trabajo que tiene cada persona, es decir, se selecciona la que es relevante para cada uno, de entre toda la disponible. Tengamos en cuenta también que el mensaje que llega al espectador dependerá en parte de la intención que haya querido transmitir el realizador y de la formación audiovisual que tenga el receptor (Ezquerra y Polo 2011).

Todo esto nos permite y nos obliga a generar un cambio en el modo de plantear las estrategias seguidas en los procesos de enseñanza-aprendizaje, y esto adaptado a las nuevas circunstancias sociales (Hernández y Quintero 2009, García y Osoro 2015, Adame 2009). En este sentido, existen estudios que evidencian una relación entre el uso de las TIC en la formación de los profesores con su favorable predisposición a utilizarlas dentro del aula en su posterior práctica docente (Karsenti y Lira 2011, Hammond et al. 2009, McKinney 1998, Goldsby y Fazal 2000). Esencialmente, esto es conocido como principio de isomorfismo (Martín del Pozo et al. 2013, Ezquerra, De Juanas y Martín del Pozo 2015). Este principio muestra la dificultad que tendrá el profesorado en formación en aplicar nuevas estrategias de enseñanza cuando la formación que ha recibido ha tenido como eje principal una metodología tradicional. Además, al profesorado en formación les resulta complejo visualizar planteamientos innovadores como futuros docentes, dada la falta de recursos que deriva de su déficit de experiencia (Pontes y Poyato 2016). Como señalan Porlán, Rivero y Martín del Pozo (1997) es necesaria la integración real del contenido de la disciplina y la metodología de enseñanza para consolidar el denominado "conocimiento profesional", en el cual existe una interacción entre conocimientos teóricos y la acción o la práctica.

En resumen, por una parte, se ha detectado que nuestra sociedad centrada en las TIC parece solicitar estrategias de enseñanza-aprendizaje acordes con los nuevos modos de generar, almacenar y transmitir la información; y, por otra parte, tenemos problemas para modificar el estilo de enseñanza habitual, fundamentalmente, transmisivo.

En este sentido, consideramos interesante plantear al profesorado en formación propuestas educativas que aúnen, por una parte, nuevas experiencias de aprendizaje de tipo no transmisivo y, por otra, nuevos modos de tratar los contenidos, de manera más acorde a la sociedad de la información en la que vivimos. Consecuentemente, los objetivos de este trabajo son:

- Plantear al profesorado en formación una propuesta educativa basada en la indagación a través de la creación de audiovisuales educativos.

- Analizar los efectos que esta propuesta tiene sobre el tratamiento de contenidos en grupo de docentes en formación.

\section{Diseño de la investigación}

Para llevar a cabo esta propuesta se contó con una muestra formada por tres grupos-clase de la Facultad de Educación de la Universidad Complutense de Madrid:

- Dos clases del Máster de Formación del Profesorado de Educación Secundaria y Bachillerato en la especialidad de Física y Química de los cursos 2012/2013 y 2013/2014 de las asignaturas Didáctica de la Física e Investigación, Innovación y Diseño Curricular en la Didáctica de la Química y la Física, respectivamente. En total, contamos con una muestra de cuarenta y siete alumnos agrupados en doce grupos de trabajo de tres a cuatro componentes. 
- Una clase del Grado en Maestro de Primaria del curso 2012/2013 de la asignatura Fundamentos y Didáctica de la Física. En total, sesenta alumnos repartidos en doce grupos de trabajo de tres a seis componentes.

Cada uno de los grupos descritos anteriormente realizó un audiovisual educativo que, según la decisión de cada grupo, consistió en narrar una experiencia científica o exponer unos contenidos concretos adecuados para el nivel educativo en el que darán clase en el futuro. Esto implicó llevar a cabo cada una de las fases de la elaboración de este tipo de materiales educativos, que se consideran en sí mismos un proceso de aprendizaje por indagación (Manso y Ezquerra 2014, Ezquerra, Manso, Burgos y Hallabrin 2014, Ezquerra, Burgos y Manso 2016). En la investigación que presentamos aquí, exponemos los resultados de analizar las tres fases más importantes del proceso creativo realizado por los estudiantes:

- Redacción de un texto literario donde se exponen los contenidos a tratar y se unifica de forma ordenada la información seleccionada.

- Generación del guion técnico típico del mundo audiovisual a partir del texto literario.

- Elaboración del vídeo documental.

Los materiales producidos por los grupos fueron analizados utilizando el programa Atlas.ti en su versión 6.2. El análisis, de carácter cualitativo, consistió en la búsqueda y extracción de las unidades de información presentes en los textos y los guiones. Esto nos permitió observar los contenidos principales utilizados, así como, el modo de organizarse tanto en el texto literario, como en el guion (cambio 1, C1). Posteriormente, se contrastaron con los contenidos del vídeo (cambio 2, C2). Para este análisis se utilizó un sistema de categorías (ver Tabla 1).

En conjunto, esta tarea permitió valorar la estructura de los contenidos y su evolución desde el texto literario inicial, pasando por el cambio a guion (C1) y hasta el cambio a vídeo final (C2). En resumen, se desarrollaron las siguientes tareas de investigación:

- Establecimiento de un sistema de categorías.

- Categorización de los documentos en función del sistema considerado.

- Selección de contenidos

- Tipos de contenidos

- Presentación de los contenidos

- Uso de la imagen

- Análisis de los cambios en las categorías y determinación de los tipos de progresión.

Para describir el sistema de categorías se han empleado dos rúbricas diferenciadas y adaptadas de otros autores (Porlán et al. 2011, Martín del Pozo, Rivero y Porlán 2011, Rivero, Martín del Pozo, Solís, Azcárate y Porlán 2017). 
Tabla 1. Descripción del sistema de categorías (contenidos) con sus respectivos niveles de complejidad.

\begin{tabular}{|c|c|c|c|c|}
\hline & NIVEL 1 & NIVEL 2 & NIVEL 3 & NIVEL 4 \\
\hline $\begin{array}{l}\text { SELECCIÓN } \\
\text { La cuestión es cómo } \\
\text { se seleccionan los } \\
\text { contenidos para... } \\
\text { Cuáles son los } \\
\text { criterios para } \\
\text { seleccionar los } \\
\text { contenidos a trabajar. }\end{array}$ & $\begin{array}{l}\text { Solo se tienen en } \\
\text { cuenta los } \\
\text { contenidos de tipo } \\
\text { disciplinar. Por } \\
\text { ejemplo, como en } \\
\text { los libros de texto o } \\
\text { referentes } \\
\text { académicos típicos. }\end{array}$ & $\begin{array}{l}\text { Se tienen en cuenta } \\
\text { los intereses y } \\
\text { motivaciones del } \\
\text { alumnado. Se } \\
\text { apunta hacia la } \\
\text { funcionalidad } \\
\text { personal y/o social } \\
\text { de los contenidos } \\
\text { para el alumno. }\end{array}$ & $\begin{array}{l}\text { Se tiene en cuenta } \\
\text { al alumnado y sus } \\
\text { ideas } \\
\text { (conocimientos } \\
\text { previos, emociones } \\
\text { y valores, } \\
\text { concepciones } \\
\text { alternativas...). No } \\
\text { solo se intenta, } \\
\text { sino que se } \\
\text { planifican y } \\
\text { diseñan cosas con } \\
\text { las bases de la } \\
\text { didáctica. }\end{array}$ & $\begin{array}{l}\text { Se busca la } \\
\text { metacognición o } \\
\text { reflexión del } \\
\text { alumnado sobre qué } \\
\text { conocimientos } \\
\text { aprender. }\end{array}$ \\
\hline TIPOS & $\begin{array}{l}\text { Solo se formulan } \\
\text { contenidos } \\
\text { conceptuales. } \\
\text { Pueden aparecer } \\
\text { algunos } \\
\text { procedimentales o } \\
\text { actitudinales pero } \\
\text { supeditados a los } \\
\text { conceptos. }\end{array}$ & $\begin{array}{l}\text { Se consideran } \\
\text { conceptos. Se usan } \\
\text { procedimientos o } \\
\text { actitudes como } \\
\text { conocimientos en sí } \\
\text { mismos, pero no } \\
\text { ambos. }\end{array}$ & $\begin{array}{l}\text { Se integran } \\
\text { conceptos, } \\
\text { procedimientos y } \\
\text { actitudes. }\end{array}$ & $\begin{array}{l}\text { Se busca la } \\
\text { metacognición o } \\
\text { reflexión del } \\
\text { alumnado sobre las } \\
\text { características de los } \\
\text { conocimientos a } \\
\text { aprender. }\end{array}$ \\
\hline $\begin{array}{l}\text { PRESENTACIÓN } \\
\text { La cuestión es cómo } \\
\text { se muestran los } \\
\text { contenidos. } \\
\text { Bajo qué criterio se } \\
\text { organizan, preparan, } \\
\text { jerarquizan... }\end{array}$ & $\begin{array}{l}\text { Se presentan con la } \\
\text { misma lógica que en } \\
\text { la disciplina. }\end{array}$ & $\begin{array}{l}\text { Se considera la } \\
\text { perspectiva del } \\
\text { alumnado pero } \\
\text { para acercarse a los } \\
\text { contenidos } \\
\text { disciplinares o } \\
\text { académicos. }\end{array}$ & $\begin{array}{l}\text { Los contenidos se } \\
\text { abordan desde la } \\
\text { perspectiva del } \\
\text { alumnado. Él es el } \\
\text { protagonista (sus } \\
\text { ideas previas, } \\
\text { intereses, hábitos, } \\
\text { emociones...). }\end{array}$ & $\begin{array}{l}\text { Se presentan desde } \\
\text { una perspectiva de } \\
\text { reflexión por parte } \\
\text { del alumnado } \\
\text { (metacognición). }\end{array}$ \\
\hline
\end{tabular}

El uso de la imagen en el vídeo puede ser evaluado desde muchos puntos de vista: calidad técnica, tipos de planos más frecuentes, recursos audiovisuales empleados, rigor científico, si respeta derechos de autor, si el tiempo de visualización permite ver la imagen, etc. Desde el punto de vista formativo, creímos interesante evaluar la significatividad educativa de la parte visual del documental; es decir, si las imágenes estaban relacionadas de algún modo con los contenidos tratados (Ezquerra 2010). Para valorar esta vinculación realizamos un análisis de contenido. Así, por ejemplo, si el vídeo trataba sobre velocidad y aceleración, mientras las imágenes se recreaban mostrando las bondades de la ciudad donde viven los autores -es decir, son fundamentalmente decorativas y no están relacionadas con los contenidos del tema tratado- entonces, valorábamos la secuencia con el nivel más bajo en nuestra rúbrica (ver Tabla 2).

Por el contrario, cuando la imagen era capaz de explicar el tópico científico trabajado -es decir, mostraba, describía, guiaba o relacionaba los contenidos- la escena era considerada como de un nivel más alto de significatividad visual. Algunos ejemplos de esta situación son 
escenas que mostraban distintos tipos de lentes y el comportamiento de los rayos de luz al atravesarlas o que ilustraban el fenómeno de la tensión superficial de un líquido. También, se recogieron trabajos a modo de tutorial (guía de procedimientos). Sirva de muestra la fabricación de una brújula magnética donde se describían los materiales necesarios, cómo frotar la aguja, el modo apropiado de colocarla sobre la superficie del agua, etc.

Tabla 2. Descripción de los niveles de complejidad para la categoría "uso de la imagen".

\begin{tabular}{|c|c|c|c|c|}
\hline & NIVEL 1 & NIVEL 2 & NIVEL 3 & NIVEL 4 \\
\hline $\begin{array}{l}\text { USO DE LA } \\
\text { IMAGEN }\end{array}$ & $\begin{array}{l}\text { Apenas se usa la } \\
\text { imagen o tan solo } \\
\text { decora o rellena } \\
\text { (solo lleva entre el } 0 \\
\text { y el } 25 \% \text { de la } \\
\text { información). El } \\
\text { texto es el hilo que } \\
\text { guía el desarrollo de } \\
\text { los contenidos } \\
\text { Si se baja el sonido } \\
\text { solo se capta entre el } \\
0 \text { y el } 25 \% \text { de la } \\
\text { información. }\end{array}$ & $\begin{array}{l}\text { Las imágenes } \\
\text { acompañan como } \\
\text { elemento } \\
\text { descriptivo (entre el } \\
25 \text { y } 50 \% \text { ). El texto, } \\
\text { voz en off o } \\
\text { diálogo siguen } \\
\text { siendo la base del } \\
\text { desarrollo de los } \\
\text { contenidos. } \\
\text { Si se baja el sonido } \\
\text { se capta entre el } 25 \\
\text { y el } 50 \% \text { de la } \\
\text { información. }\end{array}$ & $\begin{array}{l}\text { La imagen tiene un } \\
\text { papel relevante } \\
\text { (entre } 50 \text { y } 75 \% \text { ): } \\
\text { describe, guía, } \\
\text { muestra y relaciona } \\
\text { los contenidos..., } \\
\text { siendo } \\
\text { acompañadas por } \\
\text { el sonido. En } \\
\text { general, se } \\
\text { dramatiza el texto } \\
\text { dándole realidad. } \\
\text { Sin sonido llega a } \\
\text { entender entre el } \\
50 \text { y el } 75 \% \text {. }\end{array}$ & $\begin{array}{l}\text { Las imágenes explican } \\
\text { en detalle y casi } \\
\text { exclusividad el tópico } \\
\text { ( } 75 \text { y } 100 \%) \text { siendo } \\
\text { capaces de describir, } \\
\text { guiar, mostrar o } \\
\text { relacionar los } \\
\text { contenidos. Se suelen } \\
\text { emplear efectos } \\
\text { especiales para } \\
\text { conectar los } \\
\text { elementos que } \\
\text { conforman los } \\
\text { contenidos. } \\
\text { El texto o diálogo } \\
\text { apenas tiene } \\
\text { significación. }\end{array}$ \\
\hline
\end{tabular}

Con este sistema de categorías se pudo determinar cómo eran tratados los contenidos por cada grupo en cada uno de los documentos elaborados. Esto nos permitió analizar el nivel de progresión de cada grupo y, como consecuencia, su evolución en el tratamiento de los contenidos y el uso de las imágenes.

\section{Análisis de resultados}

De acuerdo con el sistema de categorías de la tablas 1 (contenidos) y 2 (uso de la imagen) descritas en el apartado anterior se procedió a categorizar el texto literario, los cambios C1 (de texto literario a guion) y el documento C2 (de guion a vídeo). Los resultados se muestran y discuten a continuación.

\section{Tratamiento de los contenidos para el Texto Literario}

En la totalidad de los grupos, el nivel 1 es el predominante para todas las categorías consideradas en este primer documento, es decir Selección, Tipos y Presentación de contenidos, también en Uso de la Imagen. Este hecho es algo más acusado en la selección de contenidos (83,3\%), seguido por presentación de los contenidos (70,8\%) (ver Tabla 3). Esto significa que mayoritariamente, en la elaboración del texto literario, los criterios seguidos para seleccionar los contenidos se basaron en elementos disciplinares, los tipos de contenidos fueron conceptuales exclusivamente (p.ej. un grupo de Máster expresaba: "El tiro parabólico se puede descomponer en dos movimientos perpendiculares entre sí: uno vertical y otro horizontal"), los contenidos se presentan con la misma lógica que en la disciplina y apenas se usó la imagen; es decir, el diálogo fue el hilo que guía el desarrollo del contenido. 
Tabla 3. Datos generales y comparativos entre los grupos de Máster de Secundaria (MS) y Grado de Primaria (GP) para la categoría Texto Literario.

\begin{tabular}{|c|c|c|c|c|c|c|c|c|c|c|c|c|}
\hline \multicolumn{10}{|c|}{ Categoría Texto Literario } \\
\hline & \multicolumn{3}{|c|}{$\begin{array}{c}\text { Selección } \\
\text { contenidos (\%) }\end{array}$} & \multicolumn{3}{c|}{$\begin{array}{c}\text { Tipos } \\
\text { contenidos (\%) }\end{array}$} & \multicolumn{2}{c|}{$\begin{array}{c}\text { Presentación } \\
\text { contenidos (\%) }\end{array}$} & \multicolumn{3}{c|}{$\begin{array}{c}\text { Uso } \\
\text { imagen (\%) }\end{array}$} \\
\hline & Total & MS & GP & Total & MS & GP & Total & MS & GP & Total & MS & GP \\
\hline n1 & 83,3 & 83,3 & 83,3 & 66,7 & 66,7 & 66,7 & 70,8 & 75,0 & 66,7 & 62,5 & 58,3 & 66,7 \\
\hline n2 & 4,2 & 0 & 8,3 & 20,8 & 16,7 & 25,0 & 25,0 & 25,0 & 25,0 & 25,0 & 16,7 & 33,3 \\
\hline n3 & 12,5 & 16,7 & 8,3 & 12,5 & 16,7 & 8,3 & 4,2 & 0 & 8,3 & 12,5 & 25,0 & 0 \\
\hline n4 & 0 & 0 & 0 & 0 & 0 & 0 & 0 & 0 & 0 & 0 & 0 & 0 \\
\hline
\end{tabular}

El análisis comparativo indica que no hay diferencias significativas entre ambos grupos en los 4 aspectos analizados (si asumimos un nivel de error igual a 0,05). Los estadísticos de contraste, que se muestran en la Tabla 4, indican que tanto los grupos del Máster de Secundaria (MS) como los del Grado de Primaria (GP) trataron los contenidos de modo equivalente (ver Figura 1).

Tabla 4. Estadísticos de contraste de los resultados entre los grupos de MS y de GP para el Texto Literario.

\begin{tabular}{|l|c|c|c|c|}
\hline & Selección & Tipos & Presentación & Uso \\
\hline U de Mann-Whitney & 18,000 & 16,000 & 9,000 & 7,500 \\
\hline Sig. exacta [2*(Sig. unilateral)] & 1,000 &, 818 &, 180 &, 093 \\
\hline
\end{tabular}

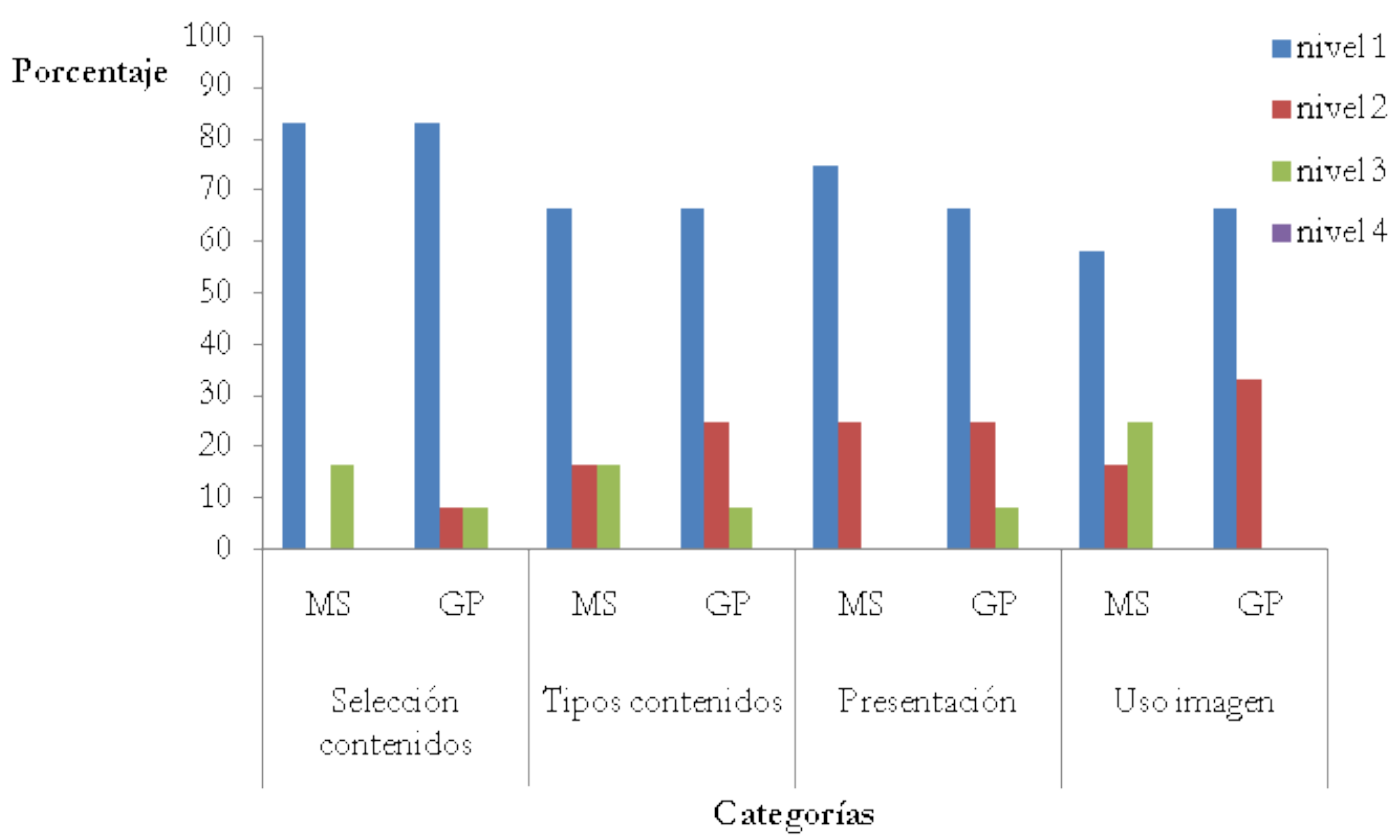

Figura 1. Análisis comparativo del tratamiento de contenidos para el Texto literario.

\section{Tratamiento de los contenidos para el cambio C1}

En este punto del proceso se observaron algunas variaciones en la gestión de los contenidos respecto a lo descrito para la creación del texto literario. Como se puede apreciar en la Figura 
2 (procedente de los datos de la Tabla 5), el nivel 1 sufre una disminución considerable, a favor de niveles superiores. Por ejemplo, para la totalidad de los grupos en la categoría "Presentación de los contenidos", el nivel 1 pasa de un 70.8\% a un 16.7\% (ver Tabla 5). También se produjeron algunas variaciones en la categoría "Uso de la Imagen", donde todos los equipos abandonaron el nivel 1 cuando se dispusieron a trabajar el guion. Esta disminución parece estar relacionada con la necesidad de transformar los contenidos del formato texto a un formato audiovisual (en el que toman parte diálogos, descripciones de planos e imágenes, efectos y rótulos). Es interesante destacar que este aumento en el uso de la imagen va más allá de lo puramente descriptivo y tiende a considerar la presencia del alumnado (p.ej. un grupo de Grado utilizó numerosos efectos sobre las imágenes con la intención de dirigir la mirada del espectador), de sus ideas (p.ej. un grupo de Grado planteaba cuestiones que guiasen la explicación y sugiriesen que podría hacer el espectador), de ciertos contenidos procedimentales (p.ej. un grupo de Máster exponía: "Plano general 2: Acercamos el imán a nuestro circuito") y actitudinales (p.ej. un grupo de Máster indicaba en el guion una alerta sobre el peligro del nitrógeno líquido) y de algunos elementos competenciales.

Tabla 5. Datos generales y comparativos entre los grupos de MS y GP para el cambio C1 de Texto a Guion.

\begin{tabular}{|c|c|c|c|c|c|c|c|c|c|c|c|c|}
\hline \multicolumn{10}{|c|}{ C1 (cambio de Texto a Guion) } \\
\hline & \multicolumn{3}{|c|}{$\begin{array}{c}\text { Selección } \\
\text { contenidos (\%) }\end{array}$} & \multicolumn{3}{c|}{$\begin{array}{c}\text { Tipos } \\
\text { contenidos (\%) }\end{array}$} & \multicolumn{2}{c|}{$\begin{array}{c}\text { Presentación } \\
\text { contenidos (\%) }\end{array}$} & \multicolumn{3}{c|}{$\begin{array}{c}\text { Uso } \\
\text { imagen (\%) }\end{array}$} \\
\hline & Total & MS & GP & Total & MS & GP & Total & MS & GP & Total & MS & GP \\
\hline n1 & 66,7 & 58,3 & 75,0 & 25,0 & 25,0 & 25,0 & 16,7 & 16,7 & 16,7 & 0 & 0 & 0 \\
\hline n2 & 4,2 & 8,3 & 0 & 62,5 & 58,3 & 58,3 & 66,7 & 75,0 & 58,3 & 25,0 & 16,7 & 33,3 \\
\hline n3 & 29,2 & 33,3 & 25,0 & 12,5 & 16,7 & 16,7 & 16,7 & 8,3 & 25,0 & 50,0 & 50,0 & 50,0 \\
\hline n4 & 0 & 0 & 0 & 0 & 0 & 0 & 0 & 0 & 0 & 25,0 & 33,3 & 16,7 \\
\hline
\end{tabular}

El análisis comparativo indica que no hay diferencias significativas entre ambos grupos en los 4 aspectos analizados (si asumimos un nivel de error igual a 0,05). Es decir, los estadísticos de contraste, que se muestran en la Tabla 6, indican que tanto los grupos del MS como los del GP trataron los contenidos de modo equivalente (ver Figura 2).

Tabla 6. Estadísticos de contraste de los resultados entre los grupos de MS y de GP para el cambio a Guion.

\begin{tabular}{|l|c|c|c|c|}
\hline & Selección & Tipos & Presentación & Uso \\
\hline U de Mann-Whitney & 16,000 & 15,000 & 15,500 & 9,000 \\
\hline Sig. exacta $2^{*}$ (Sig. unilateral)] &, 818 &, 699 &, 699 &, 180 \\
\hline
\end{tabular}

Sin embargo, al comparar las 4 categorías obtenemos un valor de Chi cuadrado igual a 30,929, cuya probabilidad asociada es de 0,000 . Por tanto, por término medio observamos que hay diferentes significativas entre ellas. 


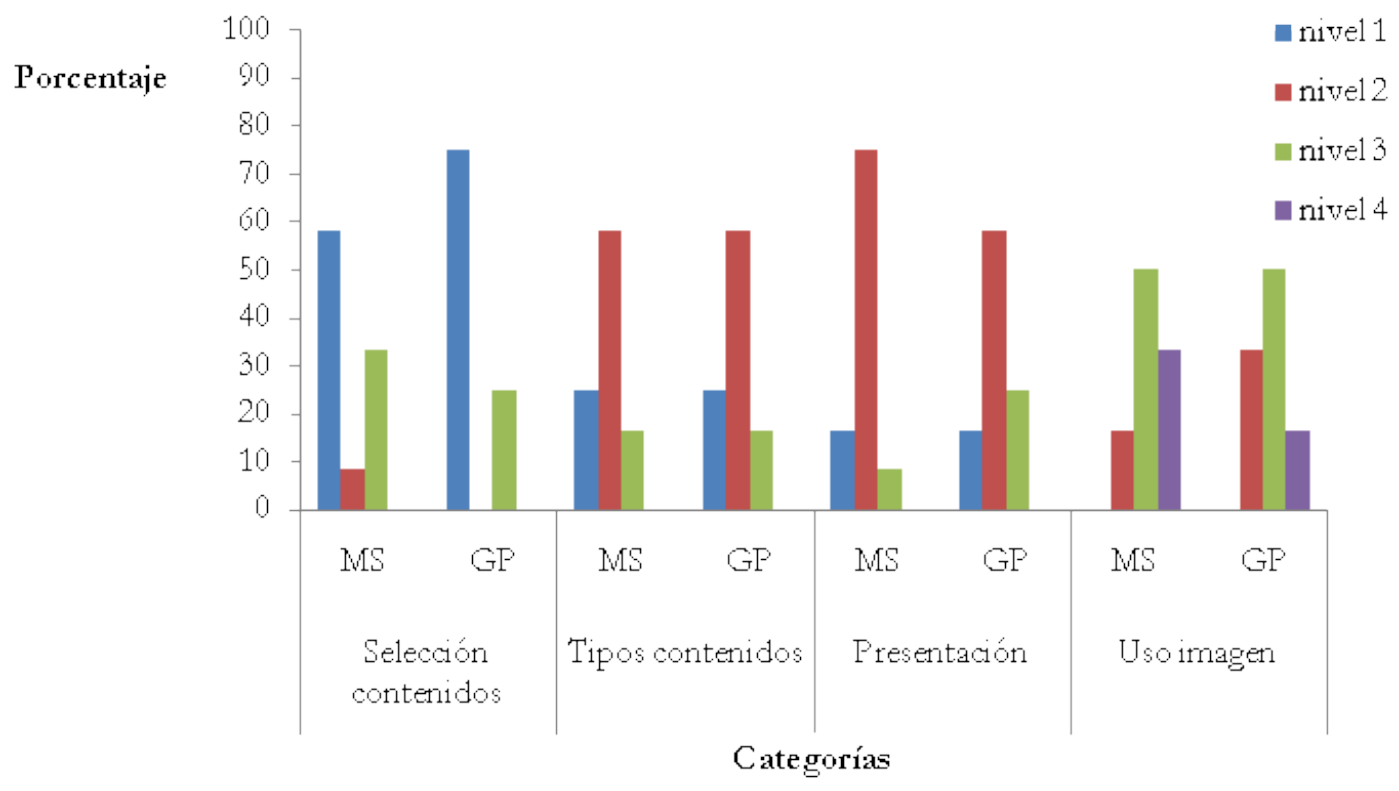

Figura 2. Análisis comparativo del tratamiento de contenidos para el Cambio C1

En la categoría "Selección de contenidos", vemos que sigue predominando el nivel 1 tanto en Máster como en Grado (58,3\% y 75\% respectivamente). A pesar de que los estadísticos de contraste no señalan diferencias significativas entre los grupos del MS y del GP, creemos oportuno indicar que, aunque los porcentajes se han reducido con respecto al texto literario, en los grupos de Grado sigue teniendo un peso importante. Ello parece implicar que éstos tienen en el Guion más en cuenta los contenidos de tipo disciplinar que los de Máster. En relación a esta categoría tanto los grupos de Máster como los de Grado, aunque continúan fieles a criterios basados en referentes académicos, comienzan a tener en cuenta al alumno, sus ideas, emociones, etc. (p.ej. uno de los grupos de Máster, en su propuesta del Guion, utiliza un lenguaje más directo hacia los supuestos alumnos espectadores, planteando cuestiones directas e indirectas hacia ellos). En este sentido, el avance hacia niveles superiores en esta categoría ha sido más acusado para los grupos de Máster que para los de Grado. Esto parece indicar que los primeros comienzan a dar cierta importancia a los intereses o las motivaciones de los alumnos y la funcionalidad social de los contenidos a la hora de seleccionarlos (p.ej. uno de los grupos de Máster expresaba en el guion: "El camino recorrido ha sido arduo y aún queda mucho por recorrer, el siguiente gran investigador puedes ser TÚ", incluyendo además una imagen de mirada hacia el futuro).

En la categoría "Tipos de contenidos" en el cambio a guion, en ambos grupos se ha dado un notable descenso en el porcentaje del nivel 1 (pasan del 66,7\% al 25\%) y un aumento considerable del porcentaje del nivel 2 (del 16,7\% al 58,3\% y del $25 \%$ al $58,3 \%$ respectivamente). Es decir, los estudiantes de ambos grupos han reducido el uso de contenidos puramente conceptuales. A su vez, más de la mitad, han recurrido más a los procedimentales que son usados como conocimientos en sí mismos (p.ej. uno de los grupos de Grado, en la parte correspondiente a cada uno de los experimentos propuestos en su Guion, expone información que incluye contenidos conceptuales y procedimentales, ya que comentan el material a utilizar, los pasos a seguir..., pero también dan una explicación abstracta de lo que sucede a modo de descripciones de hechos conceptuales como "el norte magnético de la brújula es atraído hacia el polo sur magnético de la Tierra").

En cuanto a la categoría "Presentación de contenidos", tanto entre los grupos de Máster como en los de Grado se da un desplazamiento hacia niveles superiores, principalmente al nivel 2 
(pasan de $25 \%$ a $75 \%$ en Máster y de $25 \%$ a 58,3\% en Grado). Además, aunque los resultados estadísticos no muestren diferencias significativas entre los grupos del MS y del GP, queremos indicar que apreciamos más porcentaje de estudiantes de Grado que de Máster trabajando en el nivel 3. Parece que los grupos de Grado, en el cambio a Guion, se plantean presentar los contenidos dando cierto protagonismo al alumno (a sus ideas previas, intereses, emociones, etc.).

En la categoría "Uso de la imagen" vemos que el nivel 1 pasa de ser el que mayor importancia tenía a no ser considerado, tal y como comentamos anteriormente. Se observa además un aumento notable del nivel 3 tanto en los grupos de Máster como en los de Grado. Concretamente, el 50\% de los grupos dan a la propuesta de imágenes un papel relevante, las cuales describen, guían, muestran y relacionan los contenidos. Otro aspecto a destacar es la aparición por primera vez del nivel 4 (33,3\% en caso de Máster y 16,7\% en el caso de Grado). Aunque no haya diferencias significativas, observamos, que los alumnos de Máster se inclinan en mayor medida a proponer imágenes que expliquen casi exclusivamente el contenido del tópico a trabajar (describen, guían, muestran o relacionan contenidos), mientras que los de Grado $(33,3 \%)$ se inclinan más hacia utilizarlas para acompañar como elemento descriptivo, dando aún más protagonismo a los textos y diálogos.

\section{Tratamiento de los contenidos para el cambio C2}

Esta última parte del estudio muestra el descenso progresivo del nivel 1, ya observado en el cambio $\mathrm{C} 1$, y el consecuente desplazamiento hacia niveles superiores. Bien es cierto, que este cambio se realizó con menor brusquedad que el producido al pasar del texto literario a C1. Además, parece que las imágenes en el cambio $\mathrm{C} 2$ empezaron a adquirir más importancia, no solo acompañarán como elemento descriptivo, sino que tomarán parte de la base del desarrollo de los contenidos. Prueba de ello, es que el 62,7\% de la totalidad de los grupos alcanza el máximo nivel para la categoría "Uso de la imagen" (ver Tabla 7).

Tabla 7. Datos generales y comparativos entre los grupos de MS y GP para el cambio C2 de Guion a Vídeo.

\begin{tabular}{|c|c|c|c|c|c|c|c|c|c|c|c|c|}
\hline \multicolumn{10}{|c|}{ C1 (cambio de Guion a Vídeo) } \\
\hline & \multicolumn{3}{|c|}{$\begin{array}{c}\text { Selección } \\
\text { contenidos (\%) }\end{array}$} & \multicolumn{3}{c|}{$\begin{array}{c}\text { Tipos } \\
\text { contenidos (\%) }\end{array}$} & \multicolumn{2}{c|}{$\begin{array}{c}\text { Presentación } \\
\text { contenidos (\%) }\end{array}$} & \multicolumn{3}{c|}{$\begin{array}{c}\text { Uso } \\
\text { imagen (\%) }\end{array}$} \\
\hline & Total & MS & GP & Total & MS & GP & Total & MS & GP & Total & MS & GP \\
\hline n1 & 50,0 & 33,3 & 66,7 & 20,8 & 25,0 & 16,7 & 12,5 & 8,3 & 16,7 & 0 & 0 & 0 \\
\hline $\mathrm{n} 2$ & 4,2 & 8,3 & 0 & 58,3 & 58,3 & 58,3 & 62,5 & 66,7 & 58,3 & 0 & 0 & 0 \\
\hline $\mathrm{n} 3$ & 45,8 & 58,3 & 33,3 & 20,8 & 16,7 & 25,0 & 25,0 & 25,0 & 25,0 & 37,5 & 41,7 & 33,3 \\
\hline $\mathrm{n} 4$ & 0 & 0 & 0 & 0 & 0 & 0 & 0 & 0 & 0 & 62,5 & 58,3 & 66,7 \\
\hline
\end{tabular}

El análisis comparativo indica que no hay diferencias significativas entre ambos grupos en tres de las cuatro categorías (si asumimos un nivel de error igual a 0,05). Es decir, los estadísticos de contraste, que se muestran en la Tabla 8, indican que tanto los grupos del MS como los del GP trataron la Selección, el Tipo y la Presentación de contenidos de modo equivalente, mientras en el Uso de la imagen se comportaron de modo diferente (ver Figura 3). 
Tabla 8. Estadísticos de contraste de los resultados entre los grupos de MS y de GP para el cambio a Vídeo.

\begin{tabular}{|l|c|c|c|c|}
\hline & Selección & Tipos & Presentación & Uso \\
\hline U de Mann-Whitney & 9,500 & 15,000 & 7,500 & 3,000 \\
\hline Sig. exacta [2*(Sig. unilateral)] &, 180 &, 699 &, 093 &, 015 \\
\hline
\end{tabular}

Sin embargo, al comparar las 4 categorías obtenemos un valor de Chi cuadrado igual a 44,322, cuya probabilidad asociada es de 0,000 . Por tanto, por término medio observamos que hay diferentes significativas entre ellas.

En la categoría "Selección de contenidos", al hacer el cambio de guion a vídeo, tanto en los estudiantes de Máster como los de Grado se produjo un descenso en la presencia del nivel 1 y un aumento en el nivel 3 (Figura 3). A pesar de que los estadísticos de contraste no muestran diferencias significativas, queremos apuntar que un $25 \%$ de alumnos de Máster se desplaza hacia el nivel 3 frente al 8,3\% que lo hace los de Grado. Es decir, en este punto de transformación de contenidos, la mayoría de los grupos de Máster (58,3\%) opta por tener en cuenta los conocimientos previos, las ideas, las emociones, las concepciones alternativas y los valores de los alumnos (p.ej. uno de los grupos de Máster consigue, a través de los detalles de las imágenes, mostrar cómo los propios alumnos pueden desarrollar en sus casas una experiencia sobre un fenómeno que se da en la naturaleza como es la cristalización). En los estudiantes de Grado, aunque se observa una notable presencia (33,3\%) del nivel 3, aún se conserva un $66,7 \%$ de grupos que siguen en el nivel 1, es decir, considerando criterios basados únicamente en contenidos de tipo disciplinar.

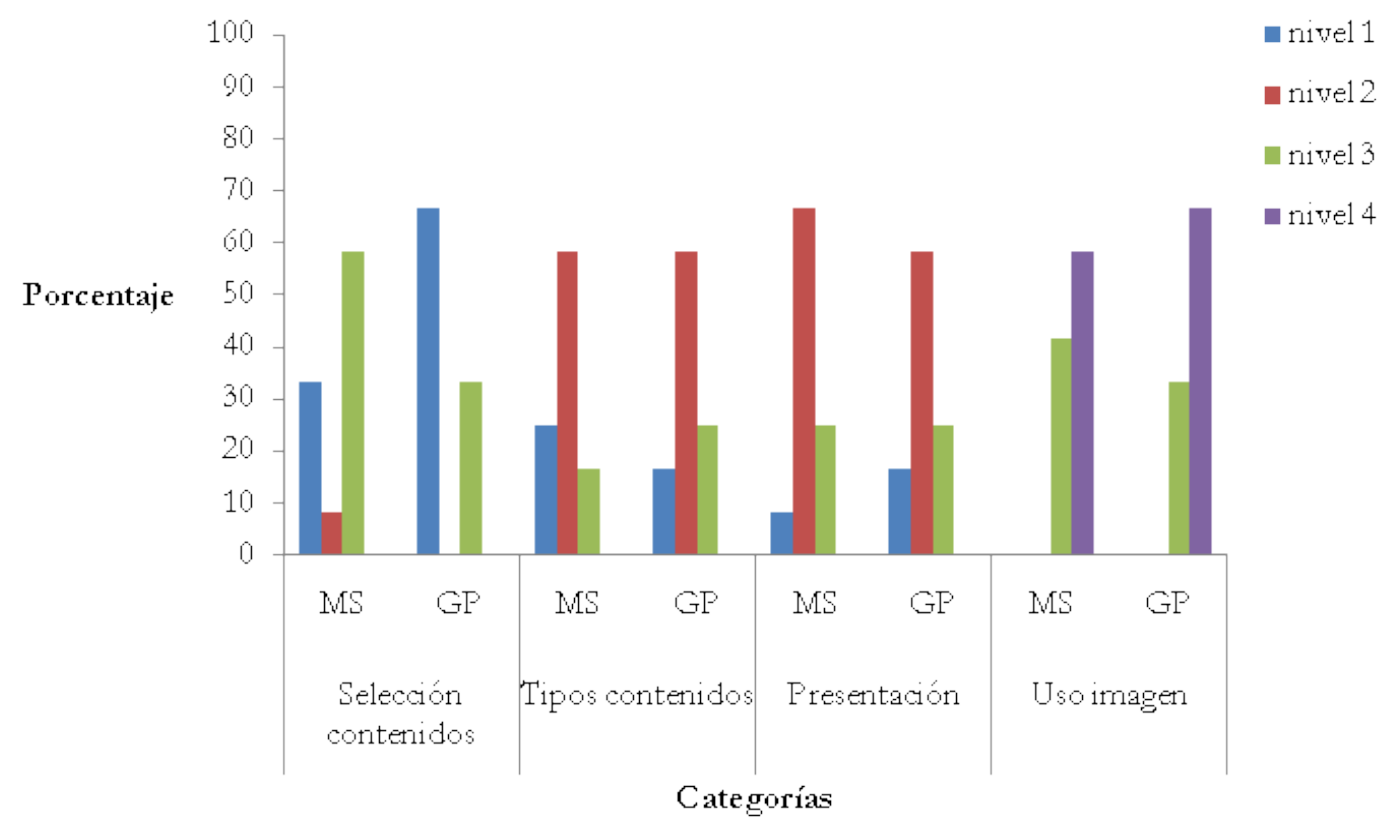

Figura 3. Análisis comparativo del tratamiento de contenidos para el Cambio C2

En el caso de "Tipos de contenidos" estamos casi en la misma situación que teníamos en C1. Es decir, dejan ligeramente de utilizar solo contenidos conceptuales para inclinarse un poco más hacia la integración de conocimientos, capacidades y actitudes.

En la categoría "Presentación de los contenidos" ambos grupos siguen teniendo el porcentaje mayoritario situado en el nivel 2 (con un 66,7\% los de Máster y un 58,3\% los de Grado). Es decir, ambos -y en especial los de Máster según nuestras observaciones- siguen considerando 
mayoritariamente la perspectiva del alumno para acercarse a los contenidos puramente académicos. Sin embargo, hay algunos grupos de Máster que además, al transformar los contenidos del guion al vídeo, han aumentado su foco de atención hacia el alumnado (en el nivel 3 pasan de un $8,3 \%$ en $\mathrm{C} 1$ a un $25 \%$ en C2). Le otorgan más protagonismo y miran un poco más desde su perspectiva. Han alcanzado en este nivel la misma representación que tienen los de Grado (25\% en C2, mismo porcentaje que tenían en C1).

En el "Uso de la imagen", tanto los grupos de Máster como los de Grado han aumentado su porcentaje en el nivel 4 abandonando, por tanto, la presencia que tenía el nivel 2 y disminuyendo el nivel 3 (los de Máster pasan del 50\% al 41,7\% y los de Grado del 50\% al $33,3 \%$ ). El hecho significativo es que este desplazamiento hacia el nivel superior es fuerte en el caso de los alumnos de Grado. Para ellos, la diferencia en el nivel 4 con respecto a C1 es del $50 \%$ (pasando de $16,7 \%$ a $66,7 \%$ ), es decir, muy considerable si tenemos en cuenta que el aumento ha sido del 25\% entre los grupos de Máster (pasando de un 33,3\% a un 58,3\%). Como era de esperar, la imagen ha cobrado una relevancia muy notable en el cambio de contenidos al formato audiovisual. Este hecho relevante, fue especialmente acusado entre los alumnos de Grado. En esta transformación de contenidos al formato Vídeo, la imagen es usada por más de la mitad de los grupos para explicar en detalle y casi exclusivamente el tópico elegido por los estudiantes, restando importancia a los diálogos y a los textos. A través de esta forma visual de representar la realidad fueron capaces de describir, guiar, mostrar o relacionar los contenidos, acompañadas en ocasiones de efectos que ayudan a conectarlos (p.ej. uno de los grupos de Máster utiliza flechas como efectos visuales para indicar la ruptura de la tensión superficial).

Aunque somos conscientes de que los resultados estadísticos no revelan diferencias significativas entre los grupos del MS y del GP, creemos oportuno hacer la siguiente apreciación: observamos que los alumnos de Máster sufrieron un desplazamiento más acusado hacia niveles superiores en las categorías "Selección de contenidos" y "Presentación de los contenidos" y los de Grado en "Tipos de contenido" y "Uso de la imagen". Podría decirse que, al producirse el cambio de Guion a Vídeo, pareció que los estudiantes de Máster tuvieron ligeramente más en cuenta las ideas de los alumnos y su perspectiva, mientras los de Grado buscaron más la integración de elementos competenciales (conocimientos, capacidades y actitudes) y la explicación de contenidos desde las imágenes.

\section{Conclusiones}

En este apartado nos vamos a centrar en las conclusiones derivadas de los datos mostrados en este trabajo, por problemas de extensión, no podemos analizar otras cuestiones. Sin embargo, queremos comentar que esta propuesta de enseñanza también se estudió a nivel motivacional. En este análisis se obtuvieron resultados que sugieren dos cuestiones. Por una parte, una fácil adaptación por parte de los estudiantes a este tipo de aprendizaje y, por otra, al menos a nivel declarativo, una alta motivación para continuar y aplicar estas tareas como parte de sus propuestas educativas futuras.

Los estadísticos de contraste no revelan diferencias significativas entre los grupos del MS y los del GP en el texto literario, en el cambio C1 y en las tres primeras categorías para el cambio C2. Sí se encuentran comportamientos diferentes en el cambio C2 para la categoría "Uso de la imagen". No obstante, vamos a tener en cuenta las observaciones que hemos ido haciendo a partir de la comparativa entre los estudiantes del Máster de Secundaria y los del Grado de Primaria. De ellas señalamos los siguientes aspectos: 
- En el texto literario, los estudiantes del MS le dieron más importancia al "Uso de las imágenes" que los del GP.

- En el cambio a Guion (C1):

- Para la "Selección de los contenidos", los estudiantes del MS se alejaron más de los contenidos de tipo disciplinar que los del GP.

- Para la "Presentación de los contenidos", los alumnos del GP tuvieron mayor tendencia a mostrarlos desde la perspectiva del alumno que los del MS.

- Para el Uso de la imagen, los estudiantes del MS se inclinaron más hacia el nivel superior que los del GP.

- En el cambio a Vídeo (C2):

- En la "Selección de contenidos", los alumnos del MS se alejaron más que los del GP de los clásicos referentes académicos comenzando, por tanto, a tener más en cuenta al alumno y sus ideas.

- En "Tipos de contenido", se observó que los estudiantes del GP se inclinaron ligeramente más hacia la integración de conocimientos, capacidades y actitudes que los del MS.

- En el "Uso de la imagen", ambos grupos se aproximaron a los niveles más elevados, aunque este hecho fue más acusado para los estudiantes de Grado.

En términos generales, puede destacarse que con el cambio de formato -de texto literario, cambio a guion y cambio de guion a vídeo- se fue produciendo un incremento desde los niveles inferiores a los superiores. Es decir, el tratamiento de los contenidos cambió desde el tradicional uso de textos hacia otras formas de mostrarlos. Esto se concretó en un mayor nivel de complejidad en la forma de abordarlos. En concreto, la utilización de otros elementos narrativos generó y potenció la presencia de otras perspectivas. La necesidad de redactar un guion forzó a los estudiantes a incorporar una trama argumental, una historia narrativa, en la que engarzar los contenidos escolares. Esta necesidad discursiva, forzó la búsqueda de situaciones reales y la consecuente ubicación de los contenidos escolares, en contextos cargados de detalles actitudinales. Esta carga de detalles actitudinales se desencadenó de forma natural en la propia creación del audiovisual. Un vídeo implica entrelazar imagen y guion; es decir, estética y contenido. Los alumnos parecieron percibir de modo muy positivo esta experiencia, e incorporaron a las situaciones ideadas por ellos, con sus gustos y sus intereses, los contenidos escolares programados en el guion (p.ej. en ocasiones, los escenarios donde tenían lugar las grabaciones de experiencias eran entornos familiares y sencillos como una cocina, un salón... denotando la posibilidad de actuar como científicos en un ambiente cotidiano. En otras ocasiones desarrollaban experiencias en laboratorios aportando cierto entorno de rigor científico). Asimismo, acompañaban estos escenarios con atuendos acordes a la situación (gafas protectoras, guantes, batas, etc.) sugiriendo, de este modo, la necesidad de protegerse de los posibles peligros.

Además, el desarrollo de una historia narrativa coherente estimuló la incorporación de diálogos y el consecuente cambio del discurso tradicional de carácter unidireccional. Este nuevo contexto narrativo facilitó la aparición de la perspectiva del alumnado, sus posibles preguntas y sus intereses, la vinculación entre su mundo y el contexto académico y, todo ello, con su modo de expresarse. Así, se propició y se dio cabida a las concepciones previas de los alumnos, los procedimientos y las actitudes. 
Por otra parte, la incorporación de imágenes obligó a los futuros profesores a realizar una descripción de los hechos en lenguaje audiovisual. Es decir, los alumnos se sintieron en la necesidad de mostrar ordenadamente procedimientos, tuvieron que considerar qué elementos visuales eran prioritarios, cuáles secundarios, cómo vincularlos, cómo indicar al espectador dónde mirar y cómo mirar. En este sentido, las imágenes pasaron a ser contenidos de aprendizaje en sí mismos.

\section{Bibliografía}

Adame Tomás, A. (2009). Medios audiovisuales en el aula. Csif Revista Digital, 19, 1-10.

Adell, J. (1997). Tendencias en educación en la sociedad de las tecnologías de la información. EDUTEC, Revista electrónica de tecnología educativa, 7, 1-15.

Ezquerra, A. (2010). Desarrollo audiovisual de contenidos científico-educativos. Vídeo: "las vacas no miran al arco iris". Enseñanza de las Ciencias, 28 (3), 353-366.

Ezquerra, A. y Polo, A.M. (2011). Requisitos para la elaboración de audiovisuales escolares. Enseñanza de las Ciencias, 29 (3), 453-462.

Ezquerra, A., Burgos, E. y Manso, J. (2016). Estudio comparativo sobre las estrategias desarrolladas por los futuros docentes de Primaria y Secundaria en la elaboración de audiovisuales educativos. Revista Eureka sobre Enseñanza y Divulgación de las Ciencias, 13(2), 493-504. http://hdl.handle.net/10498/18302

Ezquerra, A., De Juanas, A. y Martín del Pozo, R. M. (2015). Estudio sobre las actividades llevadas a cabo en la práctica docente universitaria para la formación inicial del profesorado de primaria y secundaria. Profesorado: Revista de currículum y formación del profesorado, 19 (1), 389-404.

Ezquerra, A., Manso, J., Burgos, M. E. y Hallabrin, C. (2014). Creation of audiovisual presentations as a tool to develop key competences in secondary-school students. A case study in science class. International Journal of Education and Development using Information and Communication Technology, 10 (4), 155-170.

Fischman, G. (2001). Reflections About Images, Visual Culture, and Educational Research. Educational Researcher, 30 (6), 29-33.

García, M. y Osoro, J.M. (2015). Temas clave en la formación inicial del profesorado de secundaria. Santander: Editorial Universidad Cantabria.

Goldsby, D. S., y Fazal, M. B. (2000). Technology's answer to portfolios for teachers. Kappa Delta Pi Record, 36 (3), 121-123.

Gómez, J.A. e Insausti M.J. (2004). El ciclo reflexivo cooperativo: un modelo didáctico para la enseñanza de las ciencias. Revista Electrónica de Enseñanza de las Ciencias, 3 (2), 148-160.

Hammond, M., Fragkouli, E., Suandi, I., Crosson, S., Ingram, J., Johnston-Wilder, P., Kingston, Y., Pope, M. y Wray, D. (2009). What happens as student teachers who made very good use of ITC during pre-service training enter first year of teaching? Teacher Development, 13 (2), 93-106.

Hernández, A. y Quintero, A. (2009). La integración de las TIC en el currículo: necesidades formativas e interés del profesorado. Revista Electrónica Interuniversitaria de Formación del Profesorado, 12 (2), 103-119. 
Karsenti, T. y Lira, M.L. (2011). ¿Están listos los futuros profesores para integrar las TIC en el contexto escolar? El caso de los profesores de Quebec, Canadá. Revista Electrónica de Investigación Educativa, 13 (1), 56-70.

Manso, J., Ezquerra, A. (2014). Proyectos de investigación a través de la creación de audiovisuales: propuesta de actuación con alumnos del Programa de Diversificación Curricular. Revista Eureka sobre Enseñanza y Divulgación de las Ciencias, 11 (1), 54-67. http://hdl.handle.net/10498/15712

Martín del Pozo, R., Porlán, R. y Rivero, A. (2011). The progression of prospective teachers' conceptions of school science content. Journal of ScienceTeacherEducation, 22(4), 291-312.

Martín del Pozo, R., Fernández Lozano, P., González Ballesteros, M. y De Juanas Oliva, A. (2013). El dominio de los contenidos escolares: competencia profesional y formación inicial de maestros. Revista de Educación, 360, 363-387.

Martínez-Chico, M. (2013). Formación inicial de maestros para la enseñanza de las ciencias. Diseño, implementación y evaluación de una propuesta de enseñana. (Tesis doctoral). Editorial Universidad de Almería.

McKinney, M. (1998). Preservice teachers' electronic portfolios: integrating technology, self assessment, andreflection. Teacher Education Quarterly, 25 (1), 85-103.

Novak, G. M., Patterson, E. T., Gavrin, A. D., y Christian, W. (1999). Just-in Time Teaching: Blending Active Learning with Web Technology. Upper Saddle River: Prentice Hall.

Oliva, J.M. y Acevedo, J.A. (2005). La enseñanza de las ciencias en primaria y secundaria hoy. Algunas propuestas de futuro. Revista Eureka sobre Enseñanza y Divulgación de las Ciencias, 2(2), 241-250. http://hdl.handle.net/10498/16304

Pontes, A. (2005). Aplicaciones de las tecnologías de la información y de la comunicación en la educación científica. Segunda parte: aspectos metodológicos. Revista Eureka sobre Enseñanza y Divulgación de las Ciencias, 2 (3), 330-343.

Pontes, A. y Poyato, F. (2016). Análisis de las concepciones del profesorado de secundaria sobre la enseñanza de las ciencias durante el proceso de formación inicial. Revista Eureka sobre Enseñanza y Divulgación de las Ciencias, 13 (3), 705-724.

Porlán, R., Martín del Pozo, R., Rivero, A., Harres, J., Azcárate, P. y Pizzato, M. (2011). El cambio del profesorado de ciencias II: Itinerarios de progresión y obstáculos en estudiantes de magisterio. Enseñanza de las Ciencias, 29 (3), 353-370.

Porlán R., Rivero A. y Martín del Pozo R. (1997). Conocimiento profesional y epistemología de los profesores I: Teoría, métodos e instrumentos. Enseñanza de las Ciencias, 15 (2), $155-171$.

Rivero, A., Martín del Pozo, R., Solís, E., Azcárate, P., Porlán, R., (2017). Cambio del conocimiento sobre la enseñanza de las ciencias de futuros maestros. Enseñanza de las Ciencias, 35 (1), 29-52.

Salinas, J. (2004). Cambios metodológicos con las TIC. Estrategias didácticas y entornos virtuales de enseñanza-aprendizaje. Bordón, 56 (3-4), 469-481.

Shu-Ling, L. (2000). Influence of audio-visual presentations on learning abstract concepts. International Journal of Instructional Media, 27 (2), 199-206.

Torres, M. I. (2010). La enseñanza tradicional de las ciencias versus las nuevas tendencias educativas. Revista Electrónica Educare, 14 (1), 131-142. 
Vilches, A. y Gil-Pérez, D. (2007). La necesaria renovación de la formación del profesorado para una educación científica de calidad, Tecné, Episteme y Didaxis, 22, 67-85. (Número extraordinario dedicado a los 10 años de la Revista TE). 